\title{
DOS EJEMPLOS DE RESTAURACIÓN DE PATRIMONIO ARQUITECTÓNICO INDUSTRIAL EN CATALUÑA/ESPAÑA
}

\author{
(TWO EXAMPLES OF RESTORATION OF INDUSTRIAL ARCHITECTURAL \\ HERITAGE IN CATALONIA/SPAIN)
}

\author{
Antoni Gonzalez Moreno-Navarro, Arquitecto \\ Jefe del Servicio de Patrimonio Arquitectónico Local de la Diputación de Barcelona
}

Fecha de recepción: 30-VI-97

ESPAÑA

\begin{abstract}
RESUMEN
La primera parte del artículo expone cómo el uso sinonimico de las expresiones patrimonio industrial y arqueología industrial no sólo constituye un error terminológico, sino que a menudo denuncia una mentalidad que comporta planteamientos metodológicos equivocados.
\end{abstract}

En la segunda parte, se exponen dos casos de restauración de elementos del patrimonio edificado industrial en Cataluña, la región española de más antigua tradición industrial. Se trata de dos actuaciones de la Administración, con objetivos distintos: la conservación con finalidad didáctica y la reutilización para un uso colectivo.

\section{SUMMARY}

The first part of this work explains how the synonymic use of the expressions industrial heritage and industrial archaeology is not only a terminology error, but also it often reveals a mentality bearing wrong methodological schemes.

The second part brings two restoration examples of elements from the inherited industrial buildings in Catalonia, the Spanish region possessing the oldest industrial tradition. Those are two Governmental actions with two different objectives: preservation for didactic purposes and reutilization for collective use.
El uso como sinónimos de las expresiones patrimonio industrial y arqueología industrial, además de constituir un error terminológico, denuncia a menudo una mentalidad que esconde confusiones más profundas que inducen a planteamientos metodológicos erróneos.

La arqueología, tal y como se define actualmenteel alcance de esta palabra, constituyeuna disciplina científica de investigación cuyo objeto es describir un discurso histórico basado en el análisis de los testimonios materiales. La arqueología industrial, por lo tanto, debería entenderse como el método científico de aproximación al conocimiento de la industrialización ( $\mathrm{y}$, por extensión, a la protoindustrialización) basado en el estudio de los restos materiales (edificios, máquinas, objetos, etc.) que hacen referencia a esos procesos históricos. Cabría añadir como objetivoespecífico de dicha disciplina la inventariarización previa de los objetos materiales capaces de aportar ese conocimiento.

El patrimonio arquitectónico industrial está constituido por el conjunto de elementos construidos relacionados con los procesos de fabricación, elaboración o manipulación de productos industriales o protoindustriales, que conservan sus características primitivas o han sufrido sucesivas transformaciones paralelas a la evolución tecnológica, que aún conservan su fin originario o han quedado obsoletos, y cuyo interés cultural radica (como en el caso de todos los elementos pertenecientes al patrimonio edificado en general) en dos aspectos: su valor documental e informativo, y, por otra parte, sus valores testimoniales, funcionales, técnicos o de otra índole (sentimentales o simbólicos, por ejemplo) y, en consecuencia, en su capacidad y conveniencia de reutilización. 
Un elemento construido merecedor de conocimiento y análisis por parte de la arqueología industrial puede o no formar parte del patrimonio construido industrial. Por ello, aunque de esos elementos, una vez inventariados por su valor documental, se deba intentar garantizar la extracción con el máximo rigor científico de la máxima información posible, su destino posterior (su conservación, transformación o derribo), no puede predeterminarse en función de ese valor. Sin embargo, los objetos del patrimonio arquitectónico industrial, por su propia naturaleza, deben ser protegidos y tratados según las estrategias y métodos aplicables al conjunto del patrimonio arquitectónico, estrategias y métodos que pueden aconsejar en cada caso (de acuerdo con las circunstancias condicionantes de todo tipo, por ejemplo, las urbanísticas), su conservación total o parcial, bien manteniendo (o recuperando) con fines didácticos su uso primitivo, bien procediendo a su reutilización con otros fines distintos a los originarios.

Confundir el conjunto de objetos susceptibles de ser analizados y el de aquéllos que, además, merecen ser conservados, es decir, confundir los valores exclusivamente documentales y los patrimoniales, es propio de individuos o colectivos que manifiestan un interés excesivamente focalizado ( $\mathrm{y}$ a veces excluyente) hacia una parcela determinada (tipológica, cronológica o geográfica) de la arquitectura o la ingeniería constructiva del pasado. En las últimas décadas esta confusión ha sido frecuente en el ámbito de la arquitectura o la ingeniería industrial y una de sus manifestaciones ha sido, precisamente, la errónea sinonimia a la que me refería al principio. Una consecuencia de la mentalidad que alienta esa confusión es la tendencia a exigir la conservación indiscriminada de esos objetos y de hacerlo siempre con una finalidad testimonial, con aparente olvido de las estrategias y circunstancias que condicionan esas decisiones (incluidas las de tipo presupuestario o de desarrollo urbano, incluso la modernización del parque industrial).

Justo es reconocer, no obstante, que ha sido en gran parte la labor de sensibilización emprendida por esos colectivos, interesados por los testimonios de nuestro pasado industrial, la que ha inducido a la administración pública a recuperar algunos de esos elementos.

\section{El caso paradigmático de Cataluña}

Cataluña, la región española de más antigua tradición industrial, posee consecuentemente un importante patrimonio construido de ese tipo. Su interés, tanto como objeto de análisis científico, como de testimonio de una época y una actividad cargadas de simbolismos para muchos catalanes ( $\tan$ apegados a su historia en general, por otra parte) ha producido que, alrededor de ese patrimonio, se haya despertado en Cataluña en las últimas décadas un notable interés colectivo. La existencia de la Associació del
Museu de la Ciència i de la Tècnica i de l'Arqueologia Industrial de Catalunya yla convocatoriapor esta asociación desde hace ya seis años, de los premios Bonaplata (que reconocen el trabajo realizado en la defensa y promoción del patrimonio industrial en Cataluña) son buena prueba de ese interés social. Un interés que, lógicamente, ha reportado tanto los negativos excesos conservacionistas como la positiva sensibilización pública antes aludidos, aspectos en los que también el caso de Cataluña es paradigmático.

Las dos actuaciones merecedoras de los dos últimos premios Bonaplata antes citados, el Molino de Can Batlle, en Vallirana, en 1995, y el Vapor de Ca l'Escapçat, en Sabadell, en 1996, constituyen dos buenos ejemplos de restauración y reutilización con objetivos distintos.

\section{EL MOLINO DE CAN BATLLE}

El Molino de Can Batlle está situado junto a la masía del mismo nombre, construida a partir de 1602 y englobada ahora en el casco urbano de Vallirana (comarca del Baix Llobregat, provincia de Barcelona), localidad en la que la presencia de molinos harineros está documentada desde el siglo X en el Cartulario del monasterio de Sant Cugat del Vallès.

El molino original, de una sola estancia, fue construido durante el último cuarto del siglo XV. Posteriormente fue sufriendo ampliaciones y reconversiones funcionales, algunas de ellas paralelas a la transformación de la contigua masía. En 1659 se construyó la muela volandera. mucho mayor que la del siglo $\mathrm{XV}$, que permitia moler grandes cantidades de grano. A lo largo del siglo XVIII, cuando la nueva carretera de Barcelona a Vilafranca del Penedès abrió nuevas perspectivas comerciales con la exportación de vino, se produjeron importantes modificaciones en la masía, con la construcción de nuevos espacios, de una bodega y de un establo.

A mediados del siglo XIX tuvo lugar la construcción de un molino de carácter preindustrial, abastecido por una balsa de agua de 70 metros de largo y una rueda vertical de cajones de 10 metros de diámetro, que movía las dos muelas situadas en la planta baja de la masía, justo encima del antiguo molino. En consecuencia, el molino medieval de rodezno horizontal, mucho más lento, quedó en desuso.

El nuevo molino continuó en funcionamiento hasta la segunda década del siglo XX, cuando, con la introducción de los molinos eléctricos y la implantación de potentes harineras, los molinos tradicionales tuvieron que cerrar. El de Can Batlle no fue una excepción y los molineros abandonaron el lugar.

En mayo de 1983, ante la degradación que sufría la masía, el Ayuntamiento de Vallirana -propietario ya entonces del edificio-solicitó la ayuda de la Diputación de Barcelona 
para convertirla en centro cultural de la localidad. Las obras, dirigidas por el SPAL (Servei del Patrimoni Arquitectònic Local), se iniciaron en 1987 con ese objetivo, y consistieron básicamente en la consolidación y reestructuración del interior del inmueble.

Los trabajos de investigación histórica previos o paralelos a la restauración de la masía permitieron evidenciar la importancia del molino, cuya fábrica original había quedado desdibujada tras el tiempo transcurrido, pero que conservaba intactagran parte de las maquinarias sucesivas. Los trabajos permitieron, además, confirmar la existencia de la balsa de agua relativa a la instalación preindustrial.

La antigüedad y la titularidad pública del molino de Can Batlle, sus excepcionales características (contaba con la mayor rueda hidráulica existente en Cataluña y conservaba, superpuestos, restos de los dos sistemas técnicos para obtener harina) junto a la proximidad a Barcelona de su emplazamiento (lo que permitía la expectativa de ser muy visitado) aconsejaron restaurar también esta parte del edificio con un objetivo didáctico: dar a conocer las características y la evolución de los molinos harineros hidráulicos medievales y preindustriales.

\section{EI proyecto museográfico}

Se pretendía hacer comprensible para el gran público, sobretodo el escolar, el funcionamiento del molino. Había de mostrar, además, las condiciones climáticas y orográficas que permitieron el establecimiento en la zona de muchos molinos de este tiempo.

El proyecto museográfico, basado en el estudio del historiador Jordi Amigó Barbeta, contempló que el visitante siguiera un itinerario paralelo al curso del agua, a partir de la balsa, lo que le permitiría entender conceptos como la pendiente o el volumen de agua necesarios y el uso agrícola dado al agua sobrante.

Una vez en el interior del edificio, el visitante contempla una maqueta del molino con la maquinaria en funcionamiento, así como algunos plafones explicativos, con información sobre las modificaciones sufridas por el molino a través del tiempo. Después el visitante, una vez recibida la información, puede contemplar la sala de las muelas del molino medieval con la reproducción de los mecanismos originales. En una vitrina se conservan la mesa o puente y el dado de bronce originales.

A continuación, el visitante accede a la planta superior donde una segunda maqueta y algunos plafones permiten adquirir información del molino del siglo XIX. Para apreciar los diversos engranajes se ha practicado una apertura en una pared, que permite además ver las transmisiones que hacen rodar las gruesas muelas que el visitante verá a continuación.

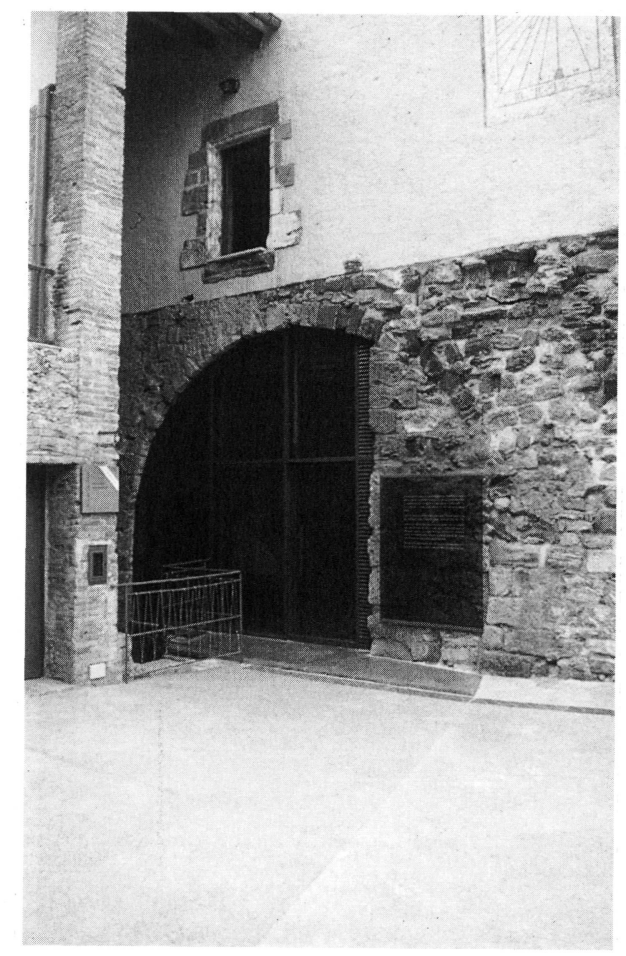

Molino de Can Batlle. Vallirana (Barcelona). Entrada principal al museo por un arco de la planta sótano convenientemente protegido para su nuevo uso. En la fachada se aprecia el reloj de sol restaurado foto: Montserrat Baldomà/SPAL).

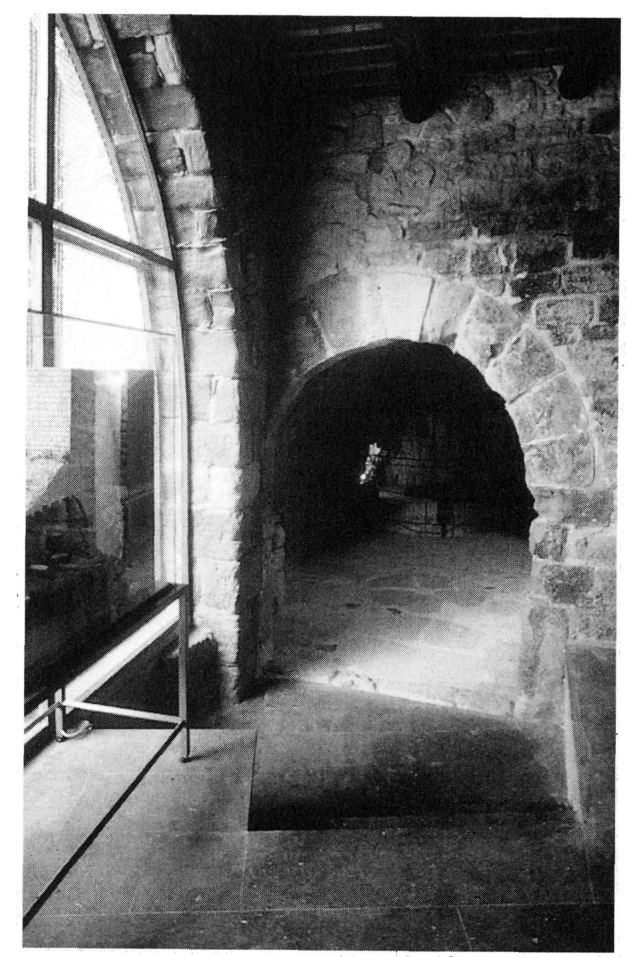

Molino de Can Batlle. Vallirana (Barcelona). Interior del vestíbulo con el acceso original al molino del siglo XV.A la izquierda, una reproducción a escala de este primer molino que explica su funcionamiento foto: Montserrat Baldomà/SPAL). 


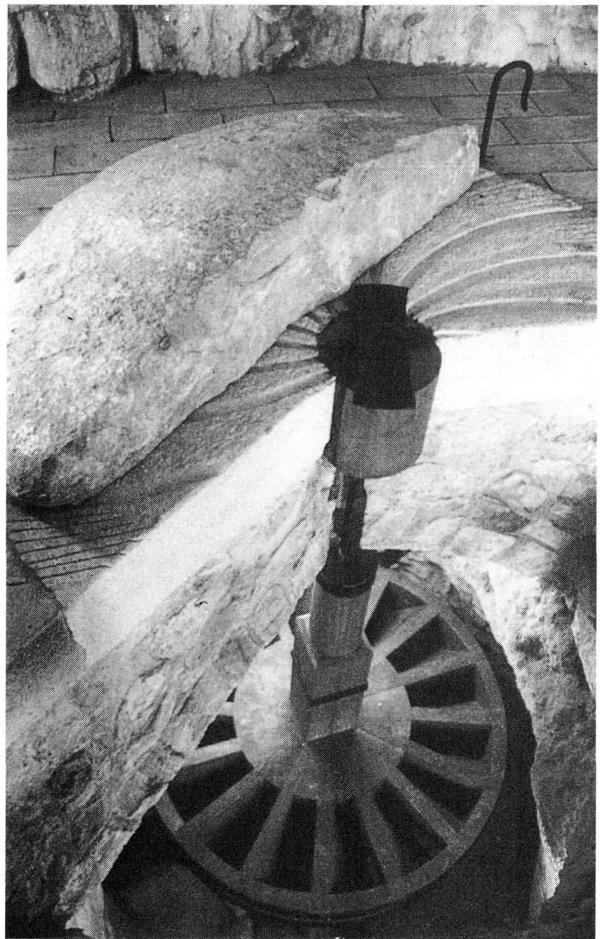

Molino de Can Batlle. Vallirana (Barcelona). Detalle del molino del siglo XV mostrado de forma seccionada para explicar didácticamente cada una de las piezas que lo componen (foto: Montserrat Baldomà/SPAL).

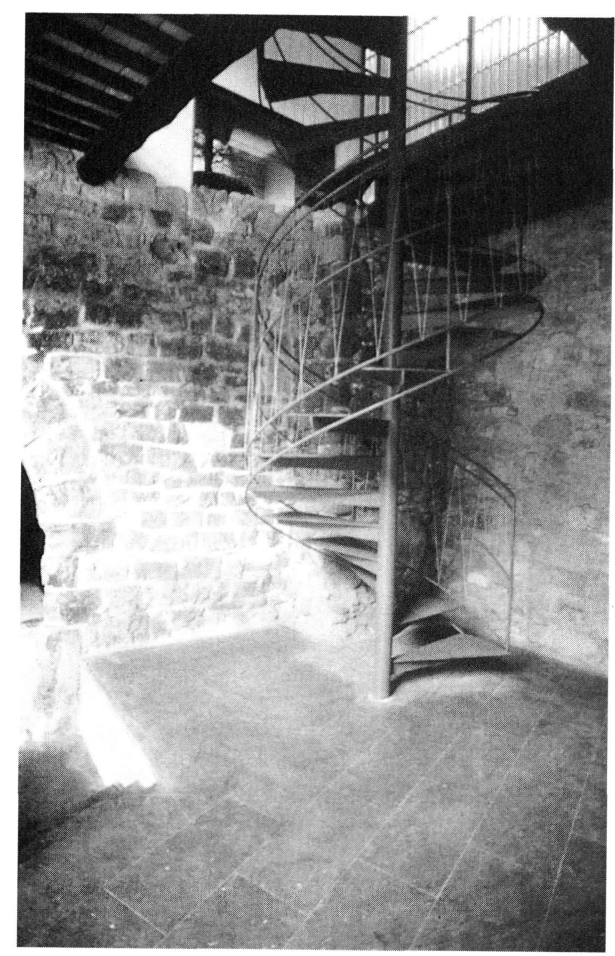

Molino de Can Batlle. Vallirana (Barcelona). Escalera de caracol que relaciona el acceso desde la planta sótano, en la que se ubica el primer molino, a la planta baja en la que se puede contemplar el molino preindustrial del siglo XLX (foto: Montserrat Baldomà/SPAL).
En la sala, una de las muelas se conserva sin las cubiertas de madera para permitir una observación directa. La otra, en cambio, se dota de todos sus elementos, de modo que el visitante puede entender cómo la harina era recogida y conducida al único agujero de salida que lleva a la harinera. A través de una ventana puede observar la rueda vertical de cajones, hecho que permite, al final de lavisita, comprender el gran avance técnico que supuso pasar de un sistema a otro.

\section{Las obras de restauración}

Las obras de restauración del molino se realizaron entre octubre de 1993 y abril de 1995 y fueron proyectadas y dirigidas por el arquitecto Josep Rovira i Pey, actual jefe del departamento de proyectos del SPAL. Tras la consolidación general de la estructura, se delimitó el espacio donde se llevaría a cabo la instalación museográfica; la planta semisubterránea, con el molino medieval, y la planta baja, con el molino del siglo XIX.

Se colocó una escalera metálica de caracol conectando las dos plantas, a la vez que se delimitaban ambas del resto de la masía con mamparas vidriadas, con el fin de dar la independencia necesaria para su nuevo uso. Se intervino entonces sobre el espacio arquitectónico de los molinos,

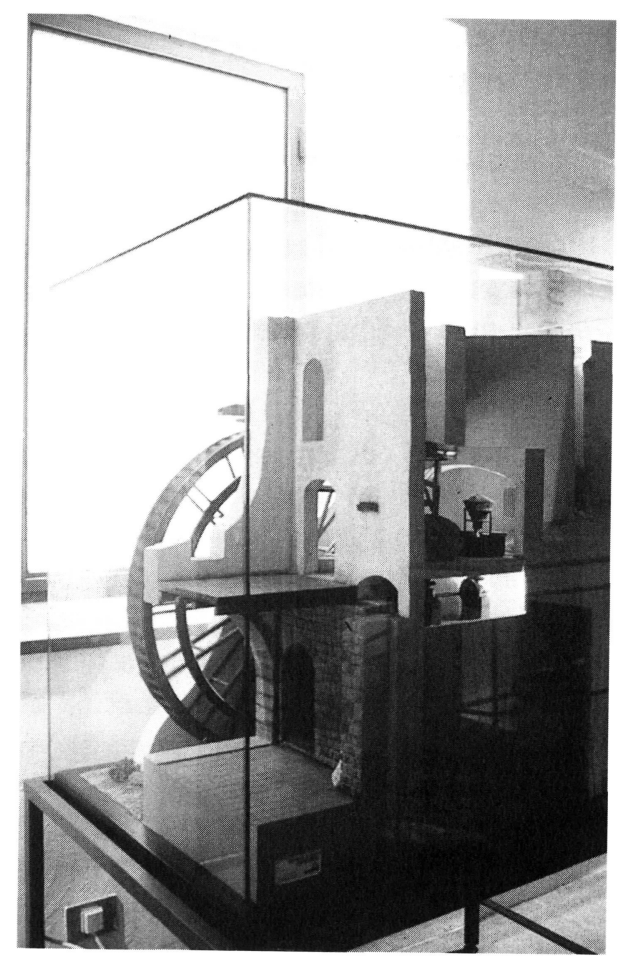

Molino de Can Batlle. Vallirana (Bareelona). Macueta explicativa del funcionamiento del molino del siglo XLY, situada en el acceso a la planta baja (foto: Montserrat Baldomà/SPAL). 


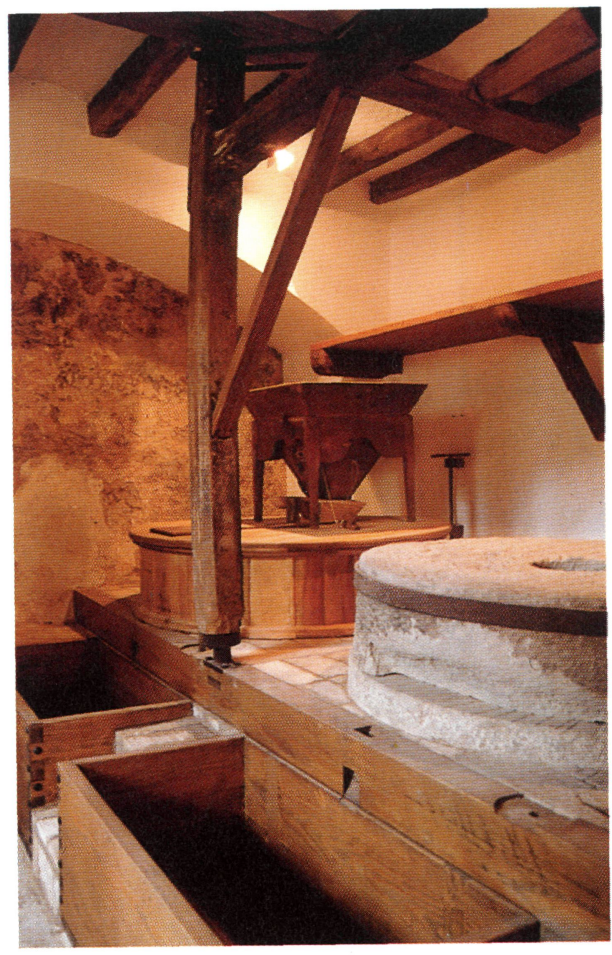

Molino de Can Batlle. Vallirana (Barcelona). Sala de las muelas del molino del siglo XLX, en la que se aprecian los elementos de un molino de la época que se han recuperado o restaurado para una visión más didáctica (foto: Montserrat Baldomà(SPAL). restaurando cada uno de sus elementos y mecanismos recuperables. Se consolidaron los muros y forjados y se recuperó el nivel original del siglo XVII con el pavimento de fragmentos de muelas colocado en aquella época.

En el cárcavo se situaron los desaparecidos mecanismos del molino del siglo XV, reproducidos por Alonso Clotet Montellà, un carpintero del pueblo de Ogern, en la comarca del Solsonès (provincia de Lérida), que con su padre ya

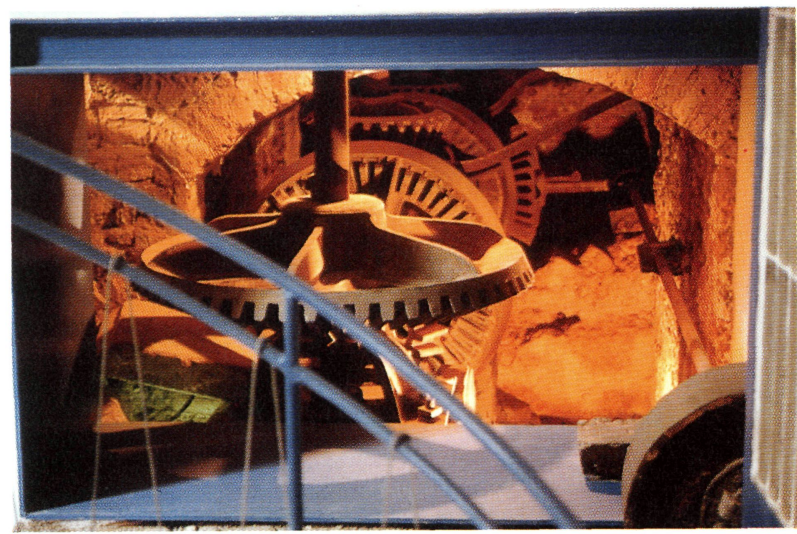

Molino de Can Batlle. Vallirana (Barcelona). Engranajes y mecanismo. de funcionamiento del molino del XLX, situados por debajo de la sala de las muelas y visibles desde la escalera de caracol que une las dos plantas del museo (foto: Montserrat Baldomà/SPAL).

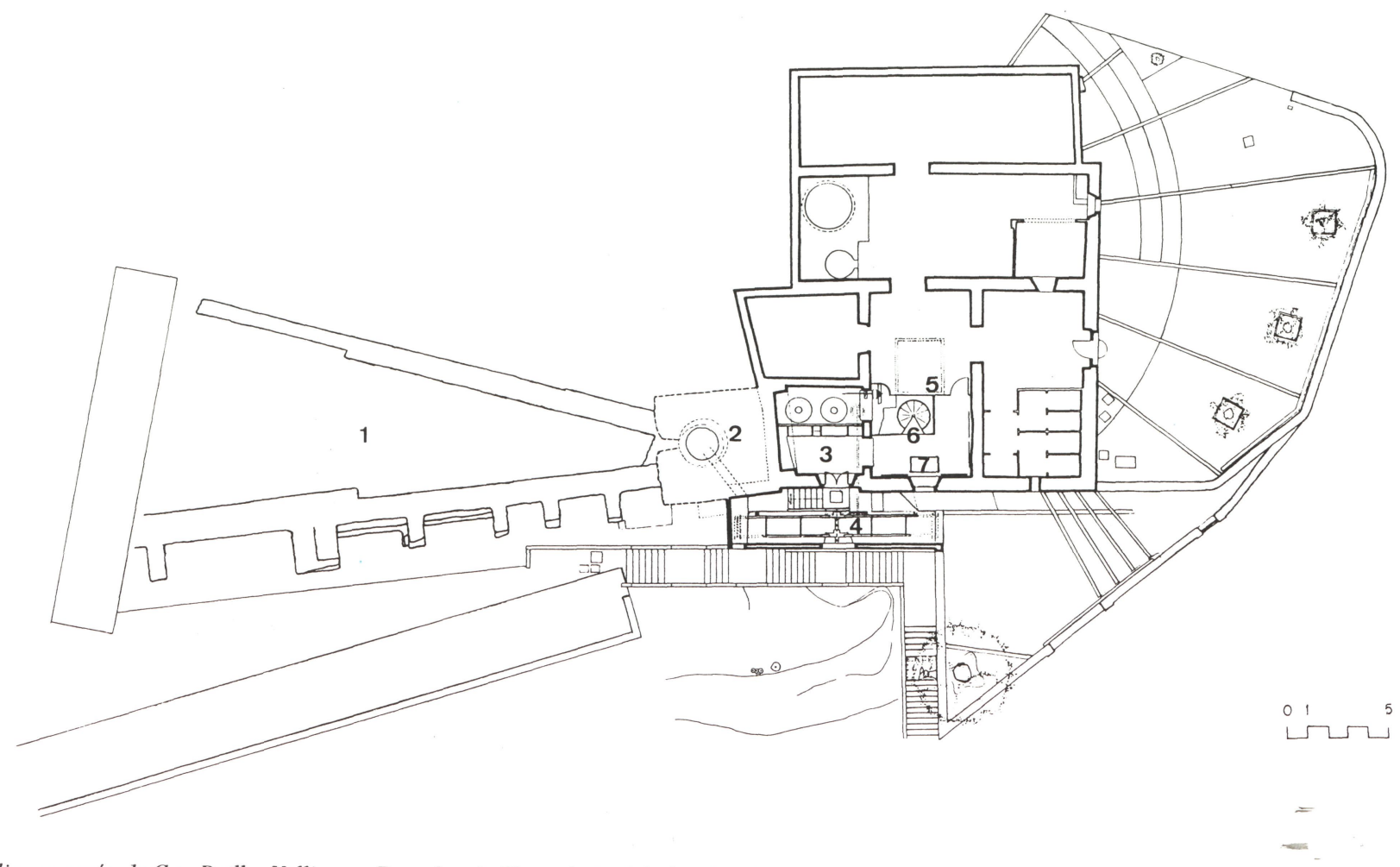

Molino y masía de Can Batlle. Vallirana (Barcelona). Planta baja. 1 balsa. 2 cubo, caz. 3 sala del molino del siglo XIX. 4 rueda de cajones (de eje horizontal). 5 tabique traslúcido divisor entre el museo y el resto de la masia, aún sin uso. 6 escalera de conexión entre las dos plantas. 7 maqueta del molino del siglo XLX.

(c) Consejo Superior de Investigaciones Científicas 


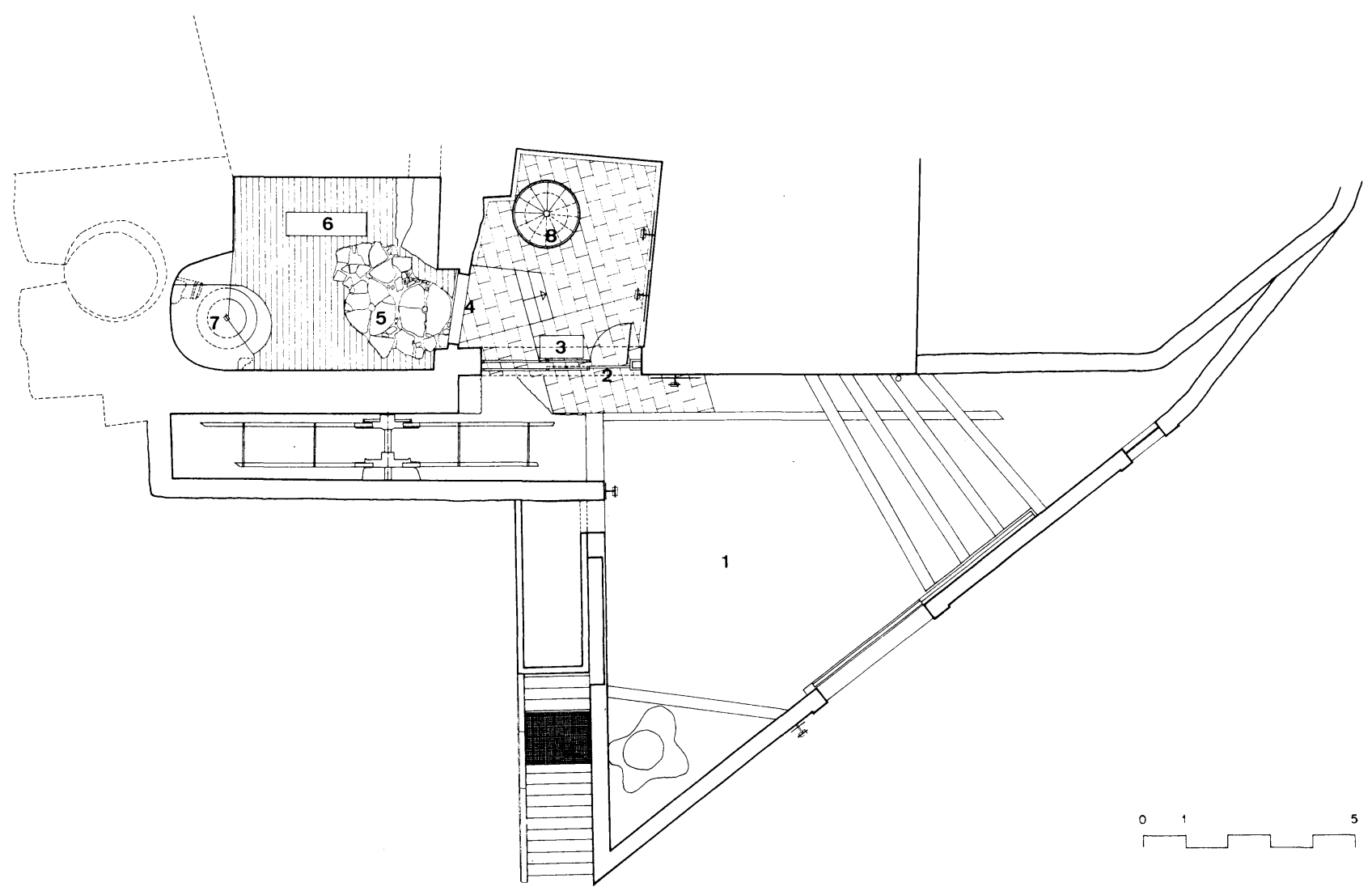

Molino de Can Batlle. Vallirana (Barcelona). Planta semisubterránea. 1 patio de acceso. 2 entrada al museo. 3 maqueta del molino del siglo XT. 4 entrada al molino del siglo $X V$. 5 pavimento a base de muelas recuperadas. 6 vitrina en la que se exponen las piezas recuperadas del antiguo molino. 7 rodezno del siglo XV. 8 escalera de comunicación entre plantas.

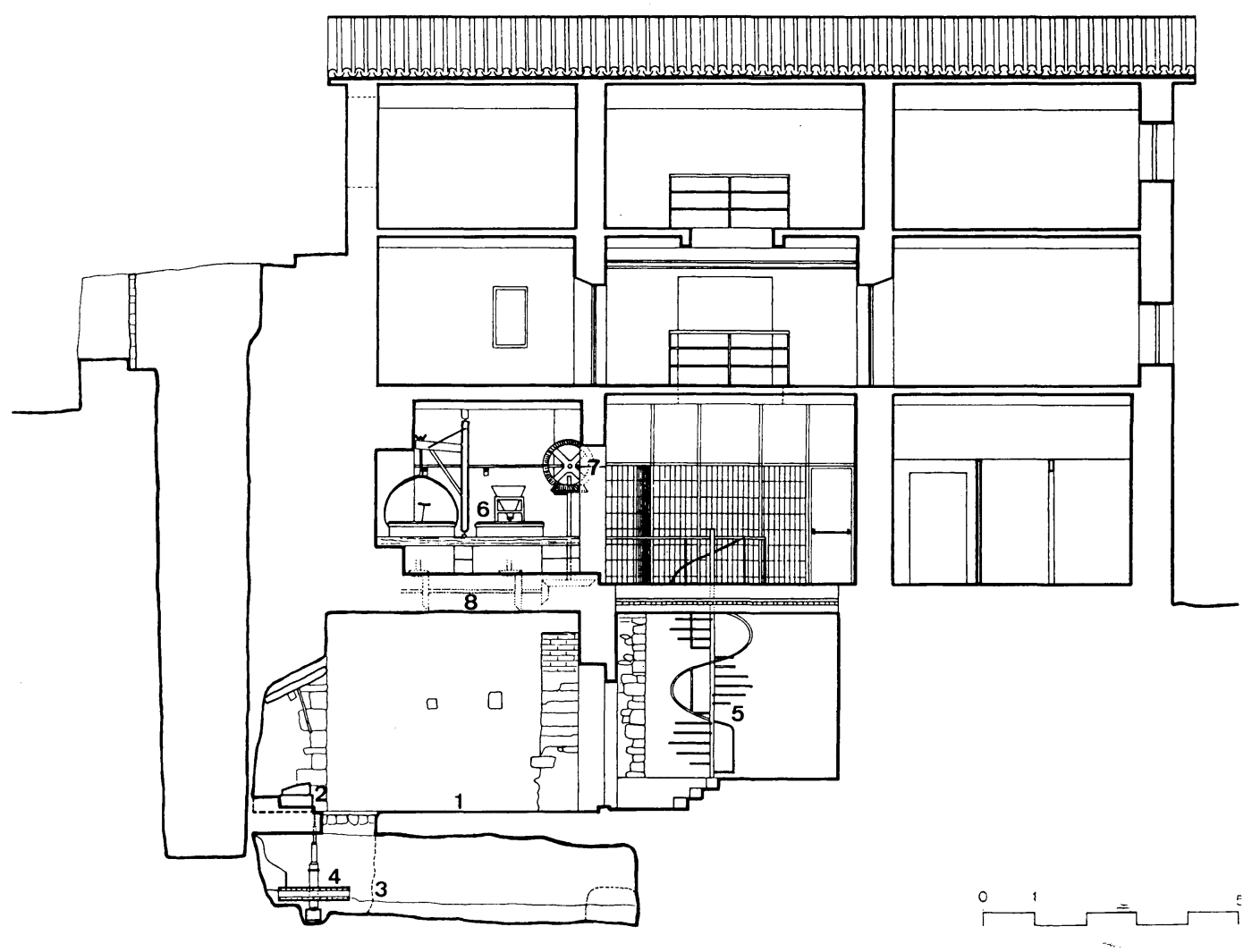

Molino de Can Batlle. Vallirana (Barcelona). Sección transversal. 1 sala del molino del siglo XV. 2 parte superior del molino (seccionada). 3 cárcavo o bóveda. 4 rodezno. 5 escalera de comunicación entre las dos salas. 6 sala del molino del siglo XLX:

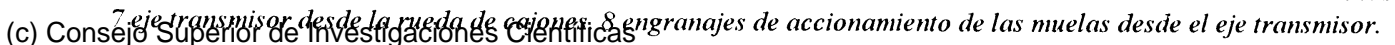




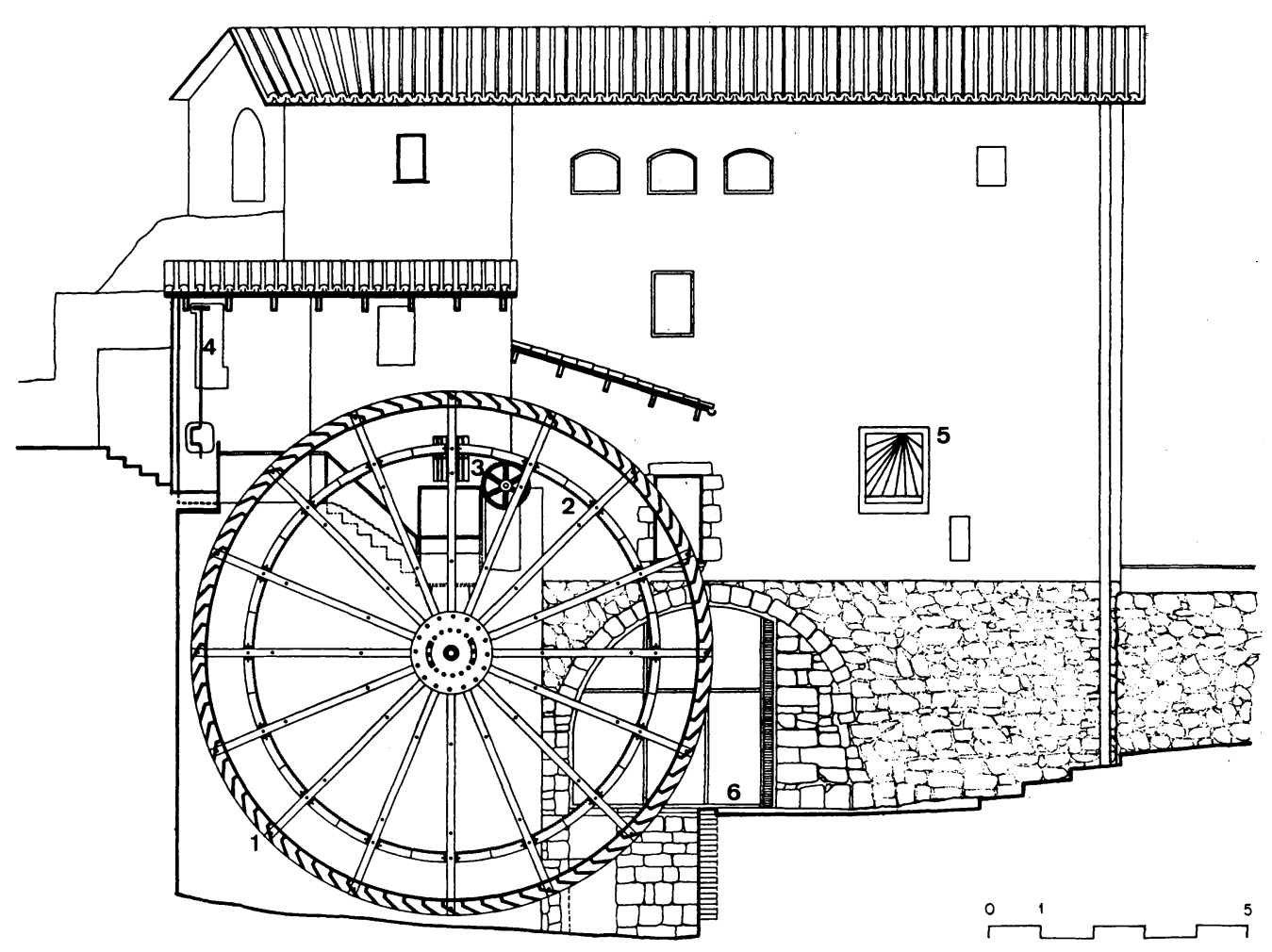

Molino de Can Batlle. Vallirana (Barcelona). Sección y fachada sur. 1 rueda de cajones de eje horizontal. 2 engranajes de la rueda. 3 eje de transmisión. 4 compuerta para el paso del agua a la canal y de ésta a la rueda. 5. reloj de sol. 6 acceso al museo.

había realizado varios rodeznos de madera antes de la irrupción de los molinos eléctricos. También se recompuso la parte superior del molino medieval, formada por el banco, la muela sotana y la muela volandera, que se muestra seccionada con una intencionalidad didáctica.

En cuanto a la sala del molino decimonónico, se recreó el ambiente original, saneando las vigas de madera y reproduciendo el pavimento original. También se reconstruyeron diversos elementos, como las partes más degradadas del banco, los brazos de hierro de la grúa y las dos harineras. El cobertizo que protege la rueda se acondicionó para su contemplación.

Finalmente, se actuó sobre el entorno inmediato, con la colocación de una puerta de malla metálica en el muro que limita el patio que antecede a la entrada del museo y la construcción de una escalera que enlazará este patio con la plaza superior, lugar de la antigua balsa de agua.

La museización del espacio fue diseñada por las interioristas Olga de la Cruz y Lourdes Borrell y el diseño gráfico corrió a cargo de Quim Boix. Las maquetas fueron realizadas por la empresa Grau-Alcázar, de Barcelona.

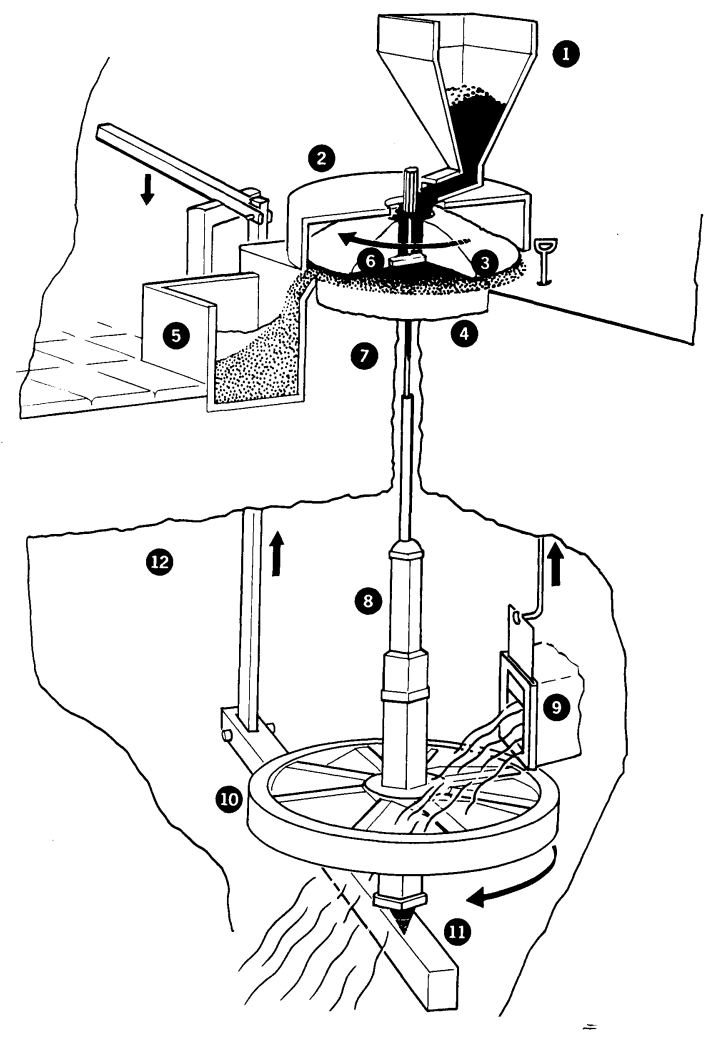

Molino de Can Batlle. Vallirana (Barcelona). Mecanismo del molino de rodezno horizontal del siglo $X V$. 1 tolva. 2 caja o guardapolvo. 3 muela volandera. 4 piedra de asiento o solera. 5 harinera. 6 lavija. 7 palahierro. 8 árbol. 9 canal. 10 rodezno. 11 mesa. 12 cárcavo o bóveda. 


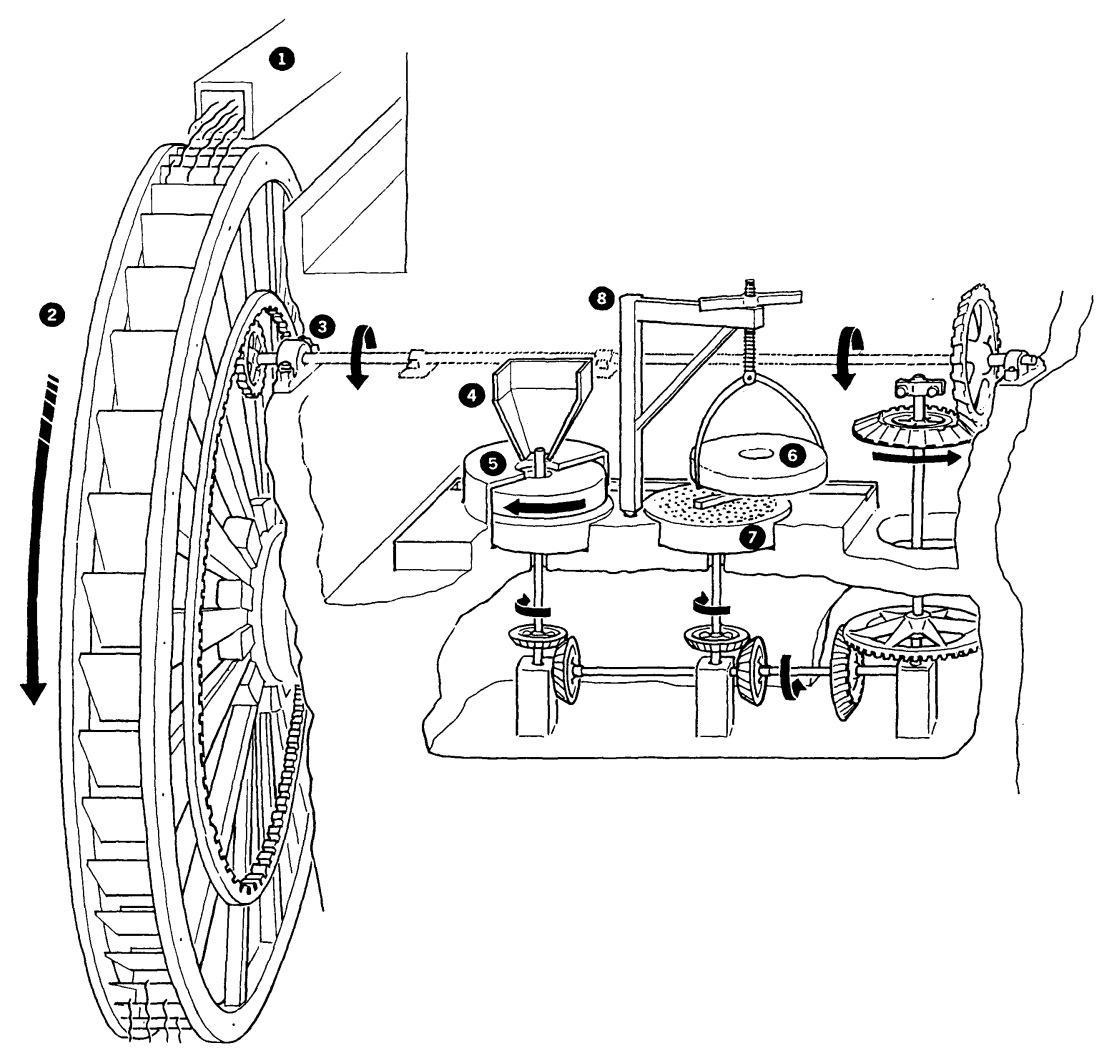

Molino de Can Batlle. Vallirana (Barcelona). Mecanismo del molino preindustrial del siglo XLX. 1 canal. 2 rueda de cajones. 3 transmisión. 4 tolva. 5 guardapolvo. 6 volandera. 7 solera. 8 grúa. 9 eje horizontal. 10 eje vertical motriz. 11 sala de engranajes.

\section{EL VAPOR DE CA L'ESCAPCYT}

El Vapor de Ca l'Escapçat, edificio construido como fábrica de gas, está situado en la ciudad de Sabadell (Vallès Oriental, Barcelona), en un territorio significado por un importante tejido industrial y una alta densidad demográfica. Responde a un tipo convencional de acuerdo con su uso y su época de construcción.

En 1991, mediante un convenio entre el ayuntamiento de Sabadell -que había adquirido el edificio- y la consejería de enseñanza del gobierno autónomo catalán se acordó la restauración del edificio para convertirlo en escuela primaria, de acuerdo con el programa aportado por los servicios técnicos de la administración autónoma, que encargó el correspondiente proyecto.

En los aspectos generales del tratamiento del edificio, el proyecto de restauración y reutilización tuvo en cuenta su clara definición tipológica como contenedor industrial de volumen compacto ubicado en un tejido urbano con notables referencias a su inmediato pasado industrial, una de las cuales era la gran chimenea de la propia fábrica a restaurar. Los modelos adoptados por los proyectistas ( en cuanto al sistema estructural, materiales a utilizar, lenguaje formal, compacidad volumétrica, relación interior-exterior, etc.), según se desprende de la memoria del proyecto, no debían alejarse de los propios del tipo.
Se consideró necesario, no obstante, derribar todos los cuerpos anexos a la nave central, restituir la geometría de la manzana mediante nuevas volumetrías, aprovechar todo el patio interior de la manzana como zona de juegos y deporte, y establecer una relación visual de éste con el interior, mediante un doble espacio resultante de la distribución de la planta baja y la colocación de todas las aulas en la primera planta.

\section{Los aspectos estructurales}

El edificio presentaba una estructura convencional de la época en que se construyó: un cierre perimetral formado por muros de fábrica de ladrillo macizo y apoyos interiores metálicos. De este mismo material eran las vigas y armaduras que cubrían la nave principal. Las bovedillas eran cerámica y carecían de capa de compresión. La estabilidad general del entramado se conseguía gracias a la fuerte rigidez de los muros perimétricos.

La primera actuación que se realizó en la nave fue la colocación de los elementos que permitieran la estabilidad y monolitismo de los forjados que se había decidido conservar. Una vez hecha la comprobación tensional de las vigas metálicas que sujetan el forjado, se reforzaron en los puntos en que pareció necesario. Después, se colocó una capa de compresión de $5 \mathrm{~cm}$, unida mediante conectores a las vigas existentes. Por otra parte, se mantuvieron y 

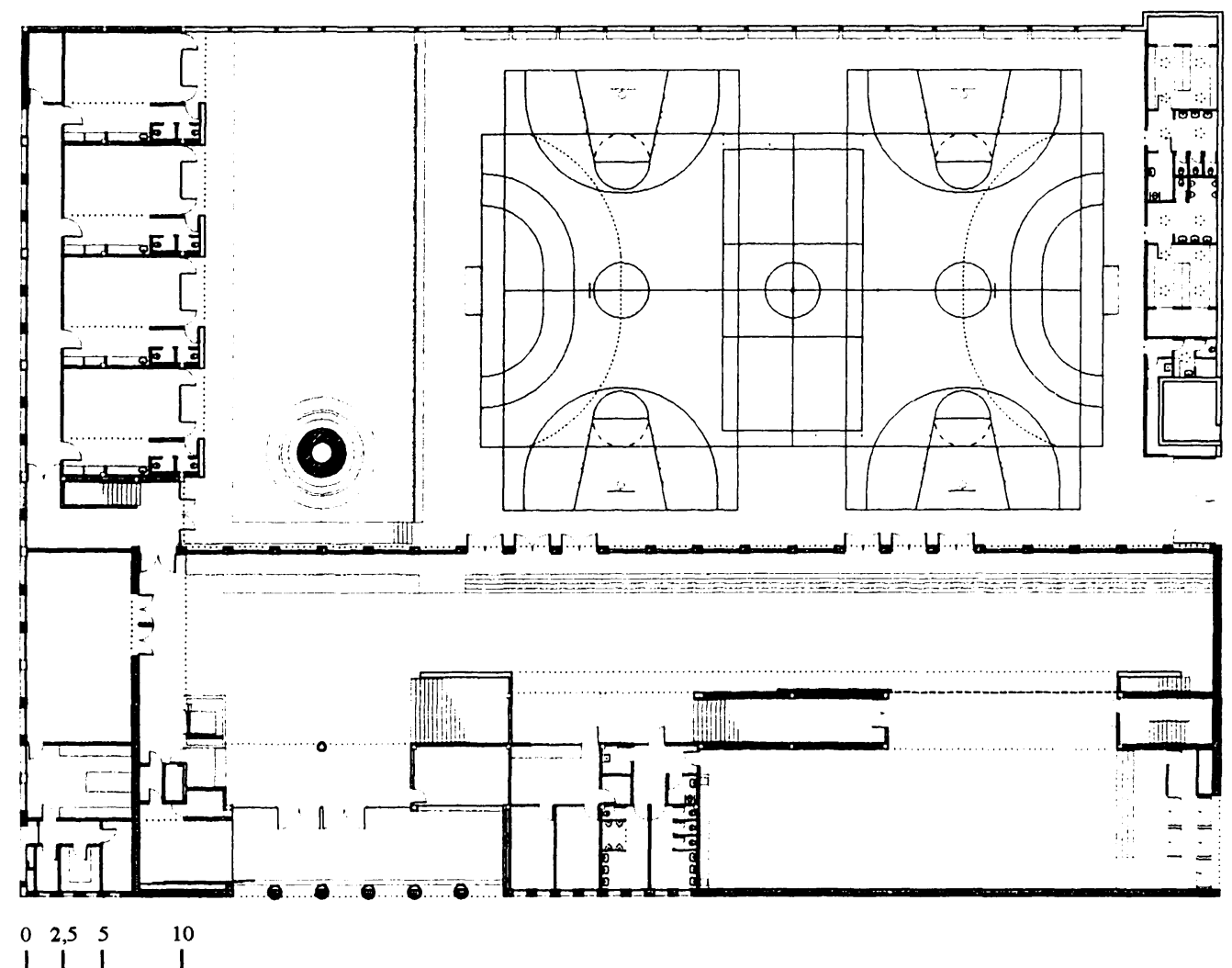

Vapor Ca l'Escap̧̧at. Sabadell (Barcelona). Planta baja.
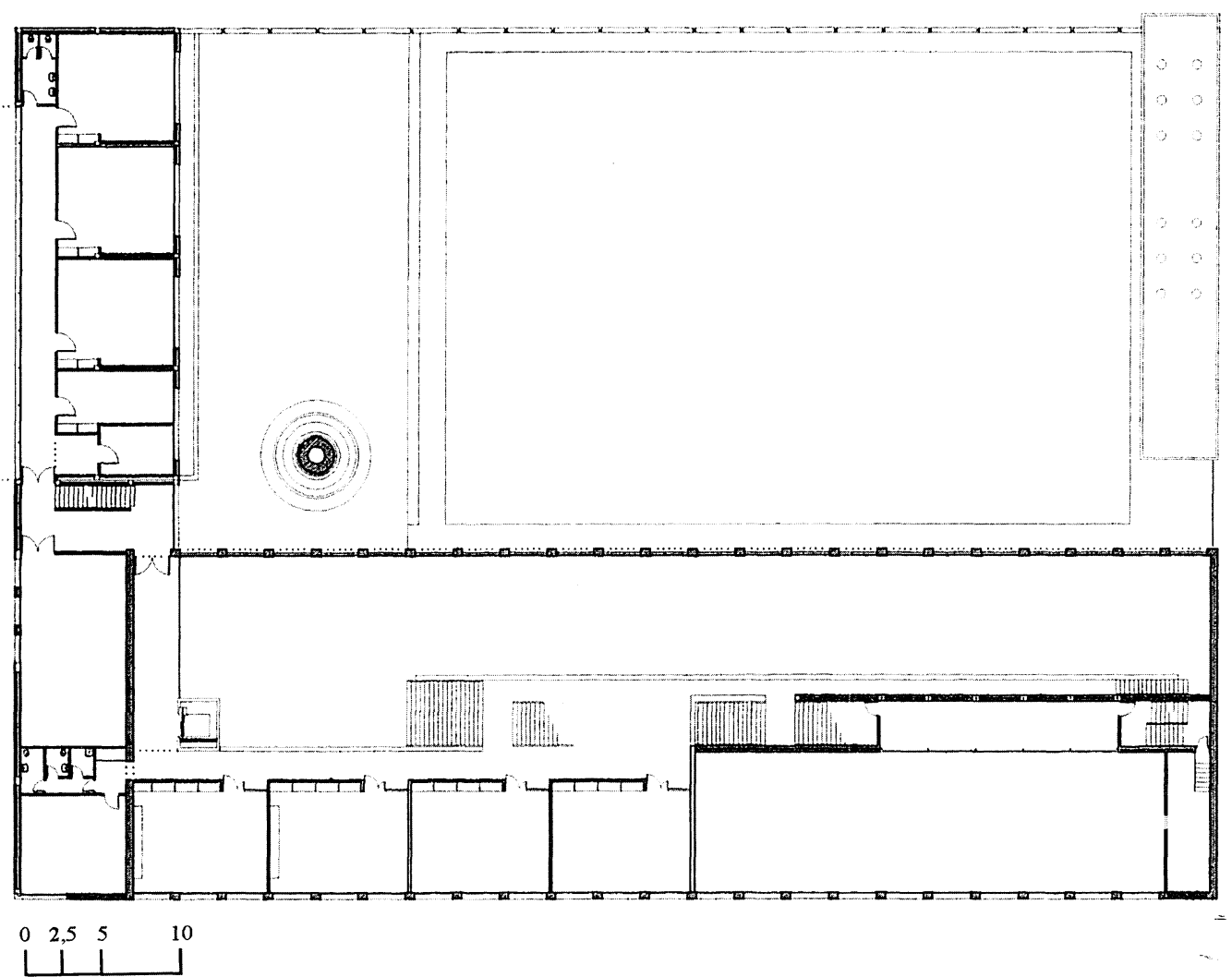

Vapor Ca l'Escap̧̧at. Sabadell (Barcelona). Planta primera. 


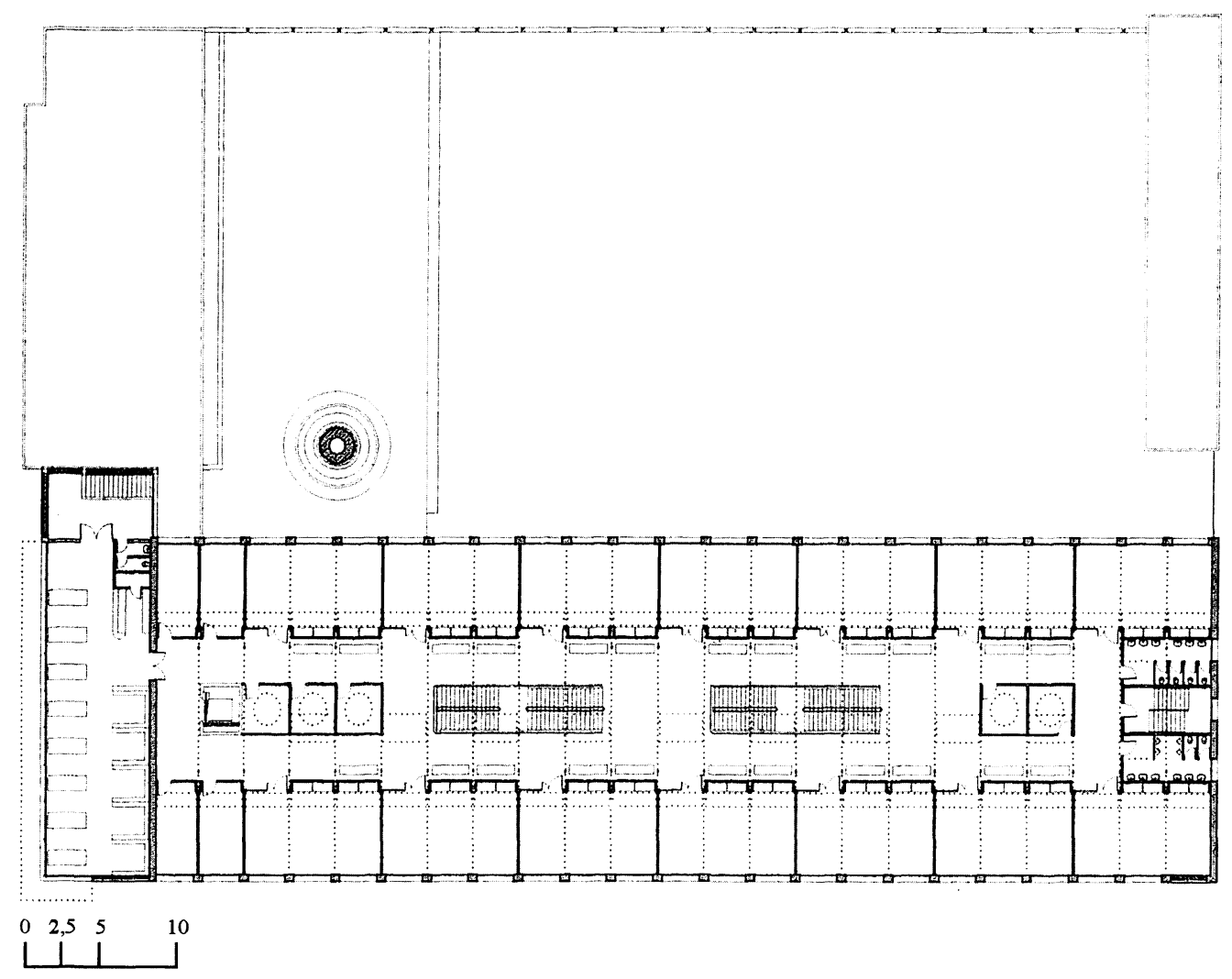

Vapor Ca l'Escap̧̧at. Sabadell (Barcelona). Planta segunda.

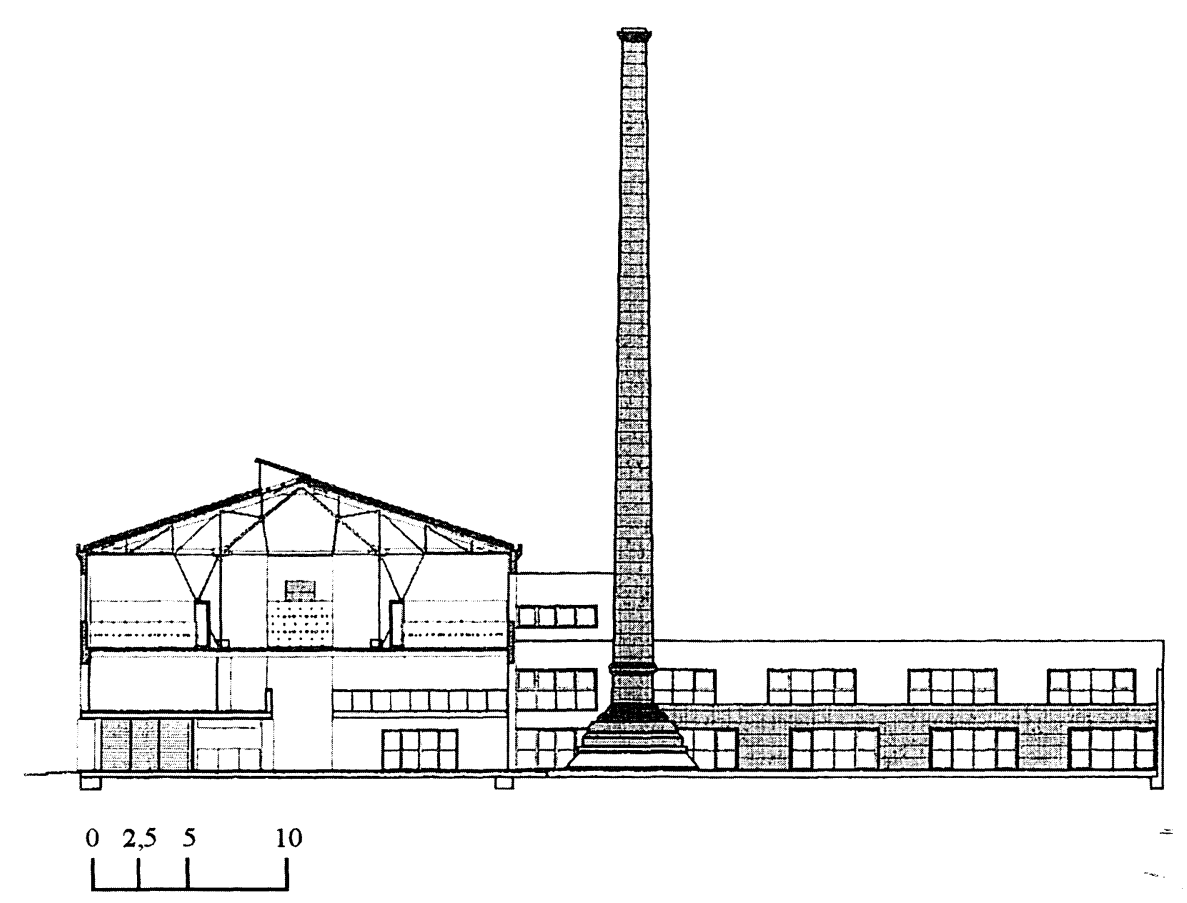

Vapor Ca l'Escap̧̧at. Sabadell (Barcelona). Sección. 


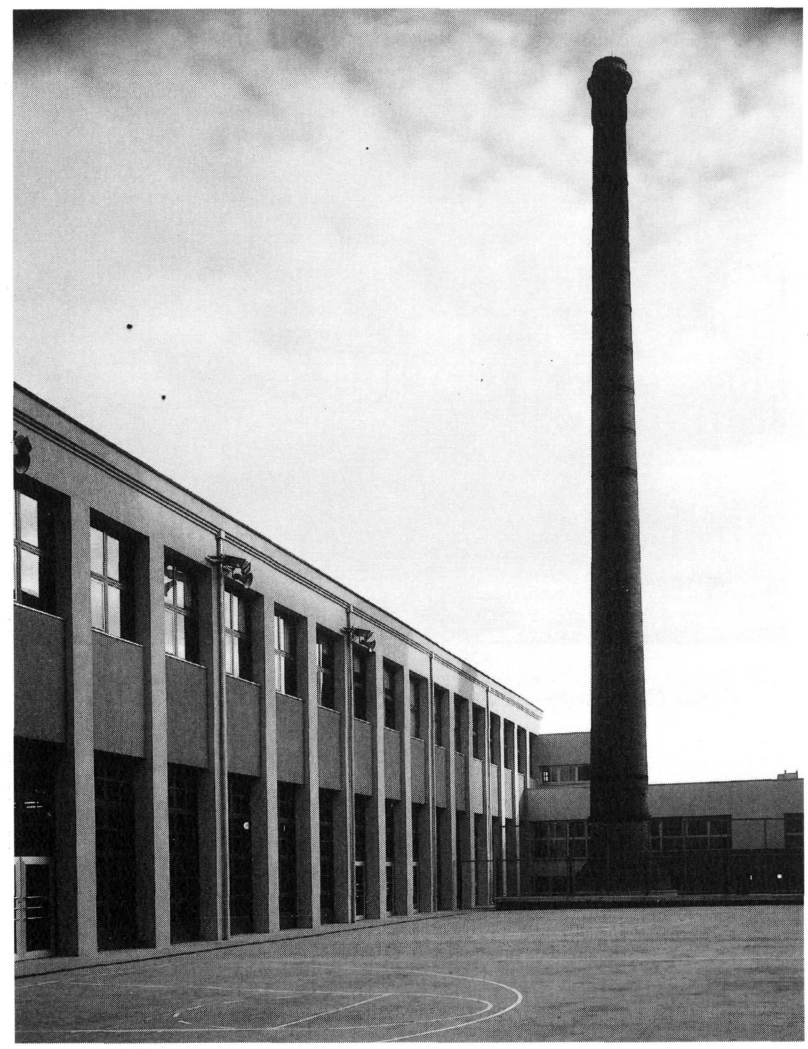

V'apor ('a l'Escapçat. Sabadell (Barcelona). Chimenea conservada y patio de juegos.

sanearon los tirantes que unían la parte inferior de las vigas metálicas que se colocaron para evitar que las bovedillas se abriesen o agrietasen.

En una segunda intervención se procedió a derribar una de las alas del edificio, compuesta por la planta baja, un piso y un subterráneo. Sobre esta superficie se levantó una nueva construcción de planta baja y dos pisos. Se bajó la cota de los pavimentos existentes, hecho que obligó a desmochar los muros que configuraban dicho subterránec para la colocación de un forjado convencional. Este nuevo forjado, formado por jácenas de arista de hormigón, se apoyó sobre el muro perimetral del subterráneo y unos pilares auxiliares de hormigón, formándose de esta manera el pavimento de la nueva planta baja. La nueva construcción constó de dos forjados convencionales formados por jácenas de hormigón y viguetas semisubterráneas sobre pilares de hormigón.

La siguiente intervención, a nivel de planta baja, trató de rebajar el nivel del pavimento del ala principal del edificio, resolviendo la nueva superficie mediante una solera de hormigón. Esta intervención dejó al descubierto la cimentación existente, formada por un muro de obra de ladrillo macizo, problema que se resolvió mediante una serie de perforaciones en todo el perímetro de la nave en la base de dicho muro, ortogonales a la cara interior de éste,

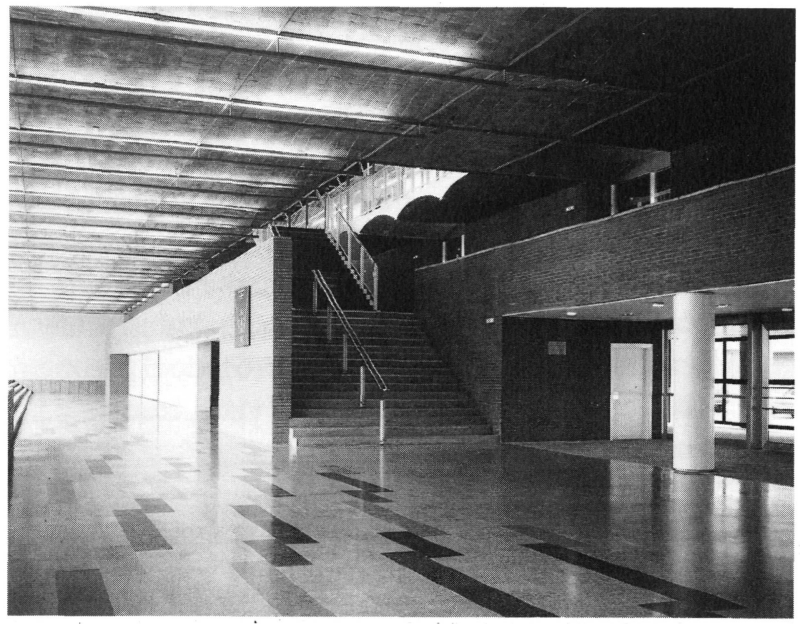

Vapor Ca l'Escapçat. Sabadell (Barcelona). Vestíbulo a doble altura y escaleras de acceso a las aulas.

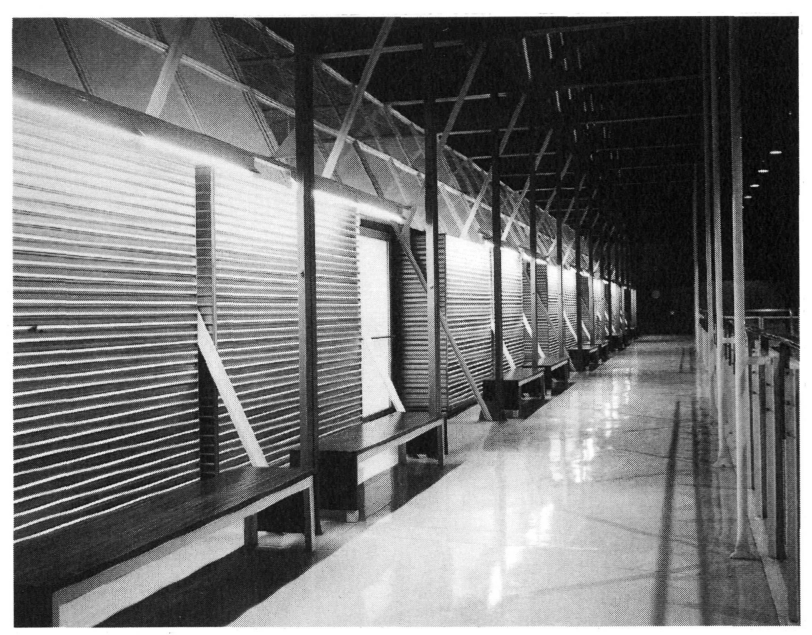

Vapor ('a l'Escapçat. Sabadell (Barcelona). C'orredor de la segunda planta y acceso a las aulas.

disponiendo redondos de acero en forma de anclaje y remachado posterior con resinas epoxídicas. También se formó una jácena de realce en todo el perímetro, mediante damas, antes de proceder al rebaje del terreno y la formación de la solera.

Otra intervención consistió en la excavación de las zanjas y pozos de los cimientos para la ubicación de pilares y muros estructurales, como elementos resistentes de la parte nueva de la obra. Ésta consta de un nuevo forjado intermedio entre el nuevo pavimento y el techo primero existente en la nave principal, que se realizó mediante viguetas semirresistentes con jácenas planas de hormigón y bovedillas cerámicas, que se extendió a la mayor parte de la superficie de la nave. 
Informes de la Construcción. Vol. 48, nº 450, julio/agosto 1997

En cuanto a la cubierta, se detectaron ciertas deformaciones en la armadura metálica, que se resolvieron mediante placas de refuerzo, con el fin de acomodarlas a la nueva normativa de cálculo y seguridad. La construcción de la nueva ala de vestuarios se llevó a cabo mediante muros resistentes de fábrica y forjado convencional de viguetas semirresistentes y bovedillas cerámicas. Finalmente, se consolidó la base de la gran chimenea mediante un refuerzo perimetral de hormigón armadoy se cerró todoel perímetro escolar con un muro de obra de fábrica vista, coronado por chapas metálicas caladas.

Los autores del proyectoy directores de las obras, realizadas en 1995, fueron los arquitectos Humbert Costas Tordera y Manuel Gómez Treviño, con quienes colaboró el arquitecto Robert Brufau en los aspectos estructurales y Manuel Comas y Jaume Gustems en las instalaciones.

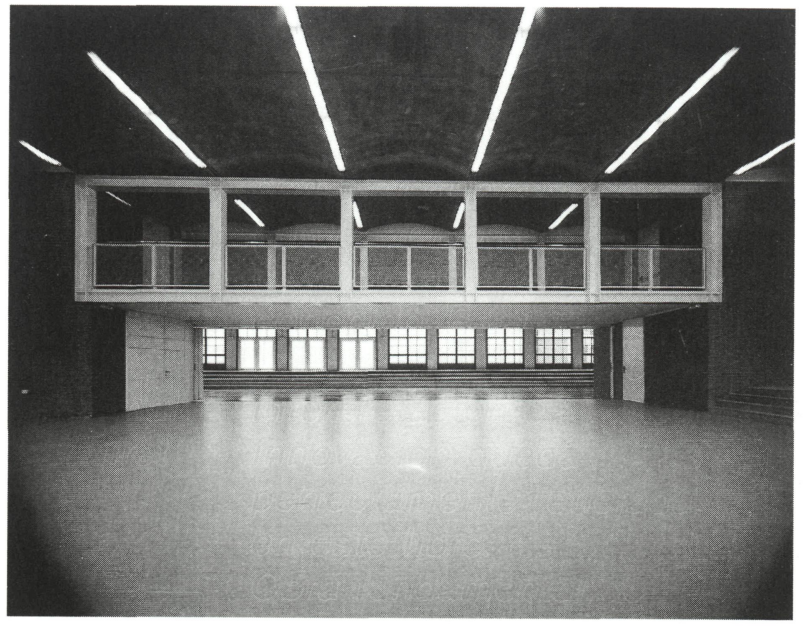

Vapor Ca l'Escapçat. Sabadell (Barcelona). Sala polivalente.

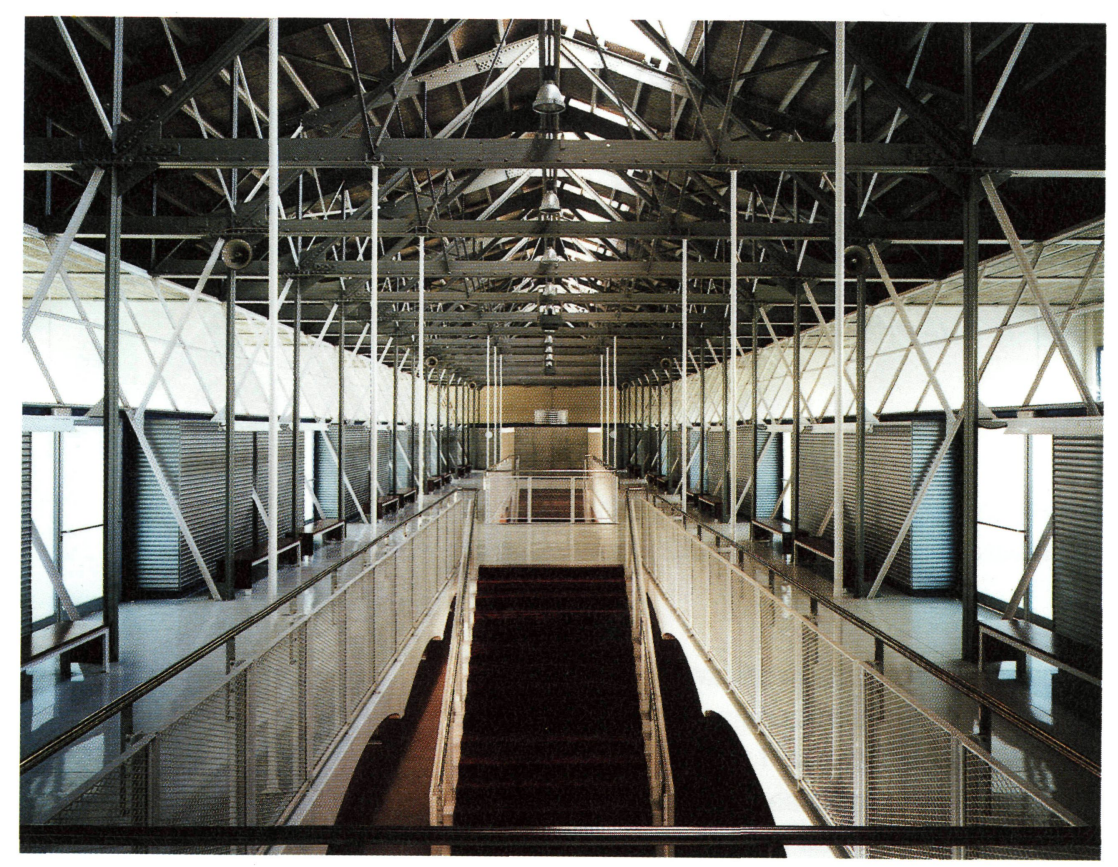

Vapor Ca l'Escapçat. Sabau'oll (Barcelona). Planta segunda. Accesos a las aulas. 